Proceedings

\title{
Evaluation of Personal Exposure to Air Pollutants and Estimation of the Inhaled Dose for Commuters in the Urban Area of Milan, Italy ${ }^{\dagger}$
}

\author{
Francesca Borghi *, Giacomo Fanti, Andrea Spinazzè, Davide Campagnolo, Sabrina Rovelli, \\ Marta Keller, Andrea Cattaneo and Domenico M. Cavallo
}

Department of Science and High Technology, University of Insubria, Via Valleggio 11, 22100 Como, Italy; giacomofanti@hotmail.com (G.F.); andrea.spinazze@uninsubria.it (A.S.); davide.campagnolo@uninsubria.it (D.C.); sabrina.rovelli@uninsubria.it (S.R.); mkeller@studenti.uninsubria.it (M.K.); andrea.cattaneo@uninsubria.it (A.C.); domenico.cavallo@uninsubria.it (D.M.C.)

* Correspondence: f.borghi2@uninsubria.it; Tel.: +39-031-238-6645

+ Presented at the 2nd International Electronic Conference on Environmental Health Sciences, 4-29 November 2019; Available online: https://iecehs-2.sciforum.net/.

Published: 1 November 2019

\begin{abstract}
The aim of this study is to evaluate a commuter's exposure to different pollutants (nitrogen dioxide $\left(\mathrm{NO}_{2}\right)$ and fractionated particulate matter (PM), including ultrafine particles (UFP)), via miniaturized and portable real-time monitoring instruments in different and selected environments; the inhaled doses of these pollutants were also estimated in each of these environments. Experimental data were collected during four working weeks, in two different seasons (winter and summer). Principal results show how higher exposures were measured in Underground (for all PM fractions and $\mathrm{NO}_{2}$ ) and in $\mathrm{Car}$ (UFP), while lower exposure levels were measured in $\mathrm{Car}\left(\mathrm{PM}\right.$ and $\mathrm{NO}_{2}$ ) and in Train (UFP). On the contrary, instead, higher values of inhaled dose were found in environments defined as Other, followed by Walking (ht-High Traffic condition), while lower values were found in Walking (lt-Low Traffic condition) and in Car.
\end{abstract}

Keywords: particulate matter; $\mathrm{PM} ; \mathrm{NO}_{2}$; air pollution; exposure assessment; micro-environment; indoor; outdoor; commuting; transport mode

\section{Introduction}

It is well known that air pollution may cause health problems and it is also well known that the adverse effects of air pollution are particularly critical in urban areas, representing hotspots especially for traffic emissions [1]. Moreover, travel micro-environments may represent settings of high exposure to different air pollutants [2]. Despite that the time spent commuting may be scarce compared to the whole day, this activity may lead to a great contribution of both exposure and inhalation of pollutants [2].

In addition to this issue, and to the need for better understanding the determinants of exposure levels in traffic micro-environments (MEs), it is important to note that most of the literature only assesses the commuters' exposures to airborne contaminants, but not the corresponding inhaled doses. However, the assessment of pollutants' inhaled dose can be of interest for risk assessment, especially in the case of commuters, because higher dose can result, owing to high exposure typically associated with urban transit/traffic environments $[3,4]$ and higher inhalation rates during active 
transport mode such as walking and cycling (i.e., increased physical effort leads to elevated inhalation rate and therefore higher inhaled dose and higher lung deposition of pollutants) [2].

The aims of this study are therefore: (i) to assess the exposure levels to different airborne pollutants measured across a commuting route, from a provincial to a big city in the Northern part of Italy; (ii) to describe pollutants' exposure levels across different MEs; (iii) to evaluate the dose of the considered airborne pollutants inhaled during daily commuting and across different MEs, considering the subject's physiological parameters; (iv) to check if different inhaled doses occur, compared to external exposure, considering different MEs.

\section{Materials and Methods}

The commuting route, fixed a priori, allowed to consider different MEs usually visited by commuters: Walking (lt-Low Traffic condition); Walking (ht-High Traffic condition); Bike; Car; Underground; Train; Indoor and Other (defined as the transition period ( $2 \mathrm{~min}$ ) between an environment to another). Experimental data were collected over two working weeks (Monday-Friday) in two different seasons, to characterize the weekly and seasonal pollutants' concentration variability.

Portable and miniaturized monitors were used to assess the exposure levels to different airborne pollutants. All the instruments were worn by one of the authors (F.G.) using a backpack. All instruments' inlets were placed in the breathing zone of the operator, or rather the hemisphere of $30 \mathrm{~cm}$ radius extending in front of the face. All instruments were set up with an acquisition rate equal to 60 s. Different portable instruments, both direct-reading and filter-based, were used to evaluate sizefractionated PM exposure. UFP exposure levels were measured via a portable diffusion size classifier (DiSCmini, Matter Aerosol AG, Wohlen AG, Swiss-DSC). The DSC used in this study can measure the number concentration and the average size of particles in the range of $10<D_{p}<700 \mathrm{~nm}$. The continuous determination of size-fractionated PM concentration was also carried out by means of a second portable direct-reading monitor (Aerocet 831-MetOne Instrument Inc., Grant Pass, Oregon, USA - Aerocet), that provides concentration data of different PM fraction ( $\mathrm{PM}_{1}, \mathrm{PM}_{2.5}, \mathrm{PM}_{4}, \mathrm{PM}_{10}$ and TSP). Finally, a complementary miniaturized monitor was used for the evaluation of $\mathrm{PM}_{2.5}$ concentration (AirBeam, HabitatMap Inc., Brooklyn, New York, USA-AB). This monitor is based on an Arduino board and it can detect particles in a range from 0.5 to $2.5 \mu \mathrm{m}$ and a $\mathrm{PM}_{2.5}$ concentration up to $400 \mu \mathrm{g} / \mathrm{m}^{3}$. PM2.5 samples were collected by means of a GK2.05 sampler (BGI Inc., Waltham, MA, USA), operating with a sampling pump with a flow rate equal to $4 \mathrm{~L} / \mathrm{min}$; particles were collected on PTFE filters. Mass concentration were determined via gravimetric analysis following a standard reference method [5,6]. UFP mass concentrations were calculated based on number concentrations, particle diameter and mean mass density factors [3].

The measurement of $\mathrm{NO}_{2}$ concentration was performed by means of a miniaturized electrochemical monitor (CairClip NO2, Cairpol, La Roche Blanche, France-CC). The evaluation of physical effort, in terms of heart rate, was evaluated using a heart rate monitor (SUUNTO 9). This instrument was also used to acquire GPS data, with the same acquisition rate of other used instruments (60 s).

\section{Results and Discussions}

During the two monitoring periods, the evaluation of pollutant exposure levels was performed across different MEs considered. Table 1 reports a descriptive statistic regarding total and seasonal (winter and summer) levels of exposure.

In order to evaluate changes and variation of exposure levels as a function of the considered MEs, a descriptive statistic of average exposure levels found across MEs is reported in Table 2. 
Table 1. Descriptive statistic performed on the total dataset (N: number of data; Min.: minimum; Max.: maximum; S.D.: standard deviation; ldsa: lung-deposited surface area; $\mathrm{PM}_{2.5}$ (AB): $\mathrm{PM}_{2.5}$ measured via AirBeam). Data are reported as $\mu \mathrm{gm}^{3}{ }^{*}$ particle $\left./ \mathrm{cm}^{3} ;{ }^{* *} \mathrm{~nm} ;{ }^{* * *} \mu \mathrm{m}^{2} / \mathrm{cm}^{3}\right)$. Data in italics refers to those used for the calculation of UFP mass.

\begin{tabular}{|c|c|c|c|c|c|}
\hline Parameter & $\mathbf{N}$ & Min. & Max. & Mean & S.D. \\
\hline UFP number * & 8179 & 212 & 74436 & 9640 & 7027 \\
\hline UFP diameter ** & 8228 & $<L O D$ & 300.0 & 49.2 & 15.2 \\
\hline UFP ldsa $a^{* * *}$ & 8228 & 0.6 & 203.9 & 24.4 & 15.9 \\
\hline UFP mass & 8239 & $<L O D$ & 197.3 & 3.7 & 4.1 \\
\hline $\mathrm{PM}_{1}$ & 8365 & 0.1 & 174.8 & 10.2 & 12.5 \\
\hline $\mathrm{PM}_{2.5}$ & 8342 & 0.2 & 160.8 & 13.1 & 15.4 \\
\hline $\mathrm{PM}_{2.5}(\mathrm{AB})$ & 7394 & 1.4 & 134.9 & 35.5 & 22.6 \\
\hline $\mathrm{PM}_{4}$ & 8348 & 0.3 & 189.0 & 16.2 & 18.9 \\
\hline $\mathrm{PM}_{10}$ & 8345 & 0.6 & 378.5 & 24.0 & 28.4 \\
\hline TSP & 8340 & 0.6 & 480.6 & 28.2 & 33.0 \\
\hline $\mathrm{NO}_{2}$ & 8690 & 0.9 & 478.5 & 30.5 & 52.7 \\
\hline
\end{tabular}

Table 2. MEs descriptive statistic (mean) performed on the total dataset. Data are reported as $\mu \mathrm{g} / \mathrm{m}^{3}$; $\mathrm{PM}_{2.5}$ (AB): $\mathrm{PM}_{2.5}$ measured via AirBeam).

\begin{tabular}{ccccccccc}
\hline & Walking (lt) & Walking (ht) & Bike & Car & Underground & Train & Indoor & Other \\
\hline UFP mass & 3.3 & 4.5 & 4.6 & 6.3 & 4.5 & 2.6 & 3.4 & 3.9 \\
PM $_{1}$ & 12.8 & 12.3 & 15.0 & 5.8 & 27.9 & 7.1 & 7.5 & 12.5 \\
$\mathrm{PM}_{2.5}$ & 15.5 & 15.2 & 19.1 & 6.8 & 42.1 & 8.2 & 9.2 & 16.3 \\
$\mathrm{PM}_{2.5}(\mathrm{AB})$ & 38.5 & 37.5 & 37.5 & 31.1 & 54.4 & 32.0 & 32.1 & 35.6 \\
$\mathrm{PM}_{4}$ & 18.6 & 19.0 & 24.6 & 7.7 & 54.8 & 9.4 & 11.3 & 20.2 \\
$\mathrm{PM}_{10}$ & 32.1 & 29.2 & 38.9 & 9.3 & 80.9 & 13.4 & 16.3 & 29.6 \\
$\mathrm{TSP}$ & 37.1 & 32.7 & 43.3 & 10.4 & 92.1 & 17.5 & 19.5 & 34.1 \\
$\mathrm{NO}_{2}$ & 32.3 & 38.5 & 44.6 & 10.8 & 66.3 & 11.9 & 29.1 & 41.1 \\
\hline
\end{tabular}

Moreover, to deeply evaluate the contribution of different PM fraction to the total, in the Figure 1 are reported the differential concentration of PM (PM1, $\left.\mathrm{PM}_{1-2.5}, \mathrm{PM}_{2.5-4}, \mathrm{PM}_{4-10}, \mathrm{PM}_{>10}\right)$ and $\mathrm{NO}_{2}$ exposure levels calculated in different MEs and during different seasons.

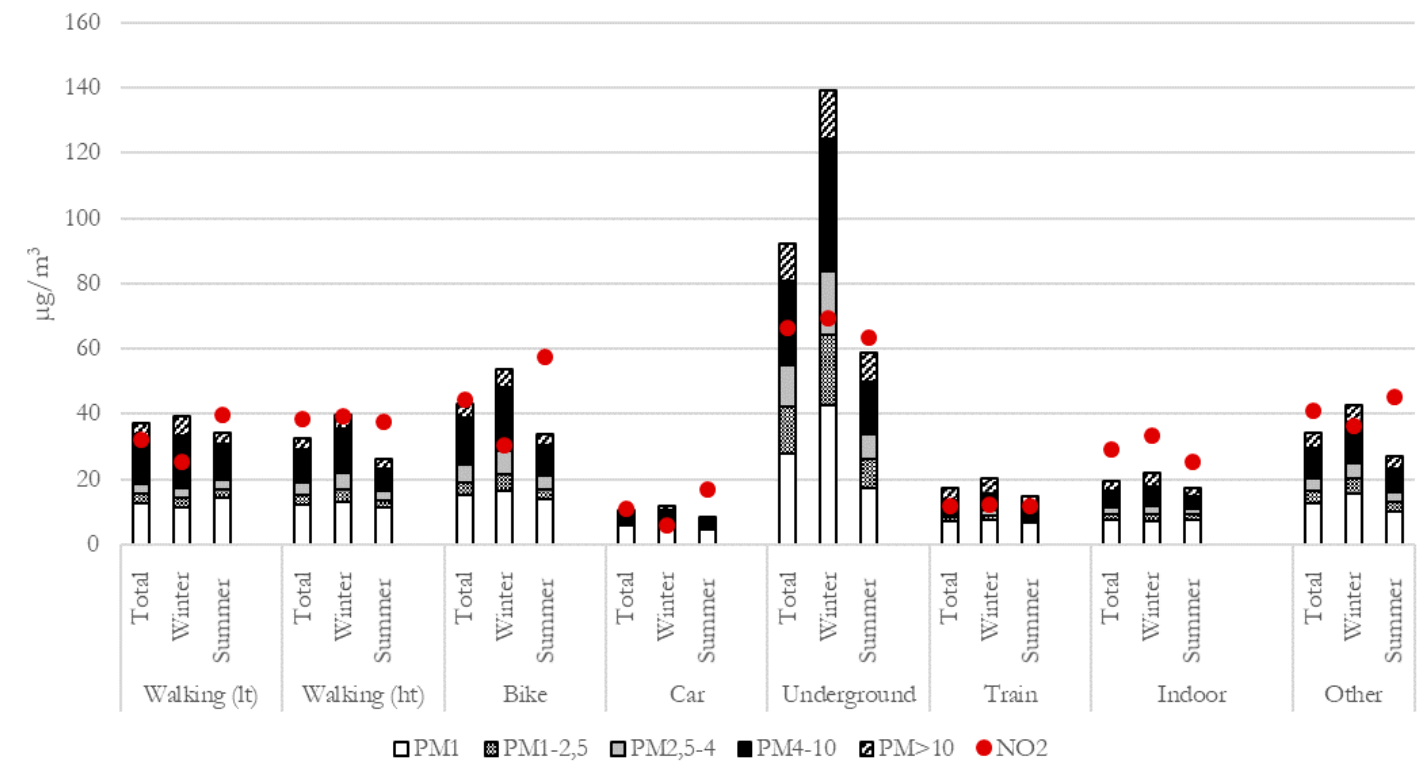

Figure 1. Differential concentration ( $\left.\mathrm{PM}_{1}, \mathrm{PM}_{1-2.5}, \mathrm{PM}_{2.5-4}, \mathrm{PM}_{4-10}, \mathrm{PM}_{>10}\right)$ and $\mathrm{NO}_{2}$ exposure levels in different MEs (reported as total, winter and summer average). 
A descriptive statistic of the inhaled dose calculated for each pollutant following Equation (1) is reported in Table 3.

$$
\text { Inhaled Dose: Conc. } \times \mathrm{T} \times \mathrm{VE}
$$

Equation (1) Inhaled Dose ( $\mu \mathrm{g})$ calculation. Conc: exposure concentration $\left(\mu \mathrm{g} / \mathrm{m}^{3}\right)$; T: time (min); VE: pulmonary ventilation rate $\left(\mathrm{m}^{3} / \mathrm{min}\right)$.

Table 3. Descriptive of the inhaled dose $(\mu \mathrm{g})$ or airborne pollutants, reported as an average for each $\mathrm{ME}$ and as total.

\begin{tabular}{cccccccccc}
\hline Pollutant & Walking (lt) & Walking (ht) & Bike & Car & Underground & Train & Indoor & Other & Total \\
\hline UFP & 0.6 & 3.8 & 1.3 & 1.5 & 1.4 & 1.7 & 2.2 & 4.9 & 17.4 \\
$\mathrm{PM}_{1}$ & 2.3 & 10.5 & 4.3 & 1.3 & 8.7 & 4.5 & 4.8 & 15.6 & 52 \\
$\mathrm{PM}_{2.5}$ & 2.8 & 13.0 & 5.5 & 1.6 & 13.1 & 5.2 & 5.9 & 20.3 & 67.4 \\
$\mathrm{AB}_{2} .5$ & 6.9 & 32.1 & 10.8 & 7.2 & 17.0 & 20.4 & 20.7 & 44.4 & 159.5 \\
$\mathrm{PM}_{4}$ & 3.3 & 16.2 & 7.1 & 1.8 & 17.1 & 6.0 & 7.3 & 25.2 & 84 \\
$\mathrm{PM}_{10}$ & 5.8 & 25.0 & 11.2 & 2.1 & 25.2 & 8.5 & 10.5 & 36.9 & 125.2 \\
$\mathrm{TSP}$ & 6.7 & 28.0 & 12.5 & 2.4 & 28.7 & 11.1 & 12.6 & 42.6 & 144.6 \\
$\mathrm{NO}_{2}$ & 5.8 & 32.9 & 12.8 & 2.5 & 20.7 & 7.6 & 18.7 & 51.3 & 152.3 \\
\hline
\end{tabular}

In general, higher values of inhaled dose were found in environments defined as Other, followed by Walking (ht), while lower values were found in Walking (lt) and in Car.

\section{Conclusions}

To date, probably due to technical-logistical problems related to the real-time measurement of physiological parameters (heartbeat or ventilation rate), studies reporting data on the inhaled dose of pollutants - especially across different traffic MEs - are still limited. This study can therefore contribute to broaden knowledge about this topic in the scientific literature.

Moreover, both for the exposure assessment and for the inhaled dose estimation in traffic environments, the results deriving from available studies do not agree with each other and, indeed, very often disagree with each other. Studies regarding the evaluation of the inhaled dose of pollutants should, in any case, be conducted, trying to standardize the conditions that lead to the determination of the inhaled dose in a certain ME, in order to assess which environment (and the boundary conditions - pollutant exposure concentrations, pulmonary ventilation rate and time spent in a given $\mathrm{ME}$ ) is more or less impactful on the pollutants' inhaled dose.

Funding: This research received no external funding.

Conflicts of Interest: The authors declare no conflict of interest.

\section{References}

1. Tan, S.H.; Roth, M.; Velasco, E. Particle exposure and inhaled dose during commuting in Singapore. Atmos. Environ. 2017, 170, 245-258.

2. Dons, E.; Laeremans, M.; Orjuela, J.P.; Avila-Palencia, I.; Carrasco-Turigas, G.; Cole-Hunter, T.; AnayaBoig, E.; Standaert, A.; De Boever, P.; Nawrot, T.; et al. Wearable Sensors for Personal Monitoring and Estimation of Inhaled Traffic-Related Air Pollution: Evaluation of Methods. Environ. Sci. Technol. 2017, 51, 1859-1867.

3. Spinazzè, A.; Cattaneo, A.; Scocca, D.R.; Bonzini, M.; Cavallo, D.M. Multi-metric measurement of personal exposure to ultrafine particles in selected urban microenvironments. Atmos. Environ. 2015, 110, 8-17.

4. Spinazzè, A.; Cattaneo, A.; Garramone, G.; Cavallo, D.M. Temporal variation of size-fractionated particulate matter and carbon monoxide in selected microenvironments of the Milan urban area. J. Occup. Environ. Hyg. 2013, 10, 652-662. 
5. UNI EN 14907. Ambient Air Quality - Standard Gravimetric Measurement Method for the Determination of the PM2.5 Mass Fraction of Suspended Particulate Matter; Comite Europeen de Normalisation: Brussels, Belgium, 2005.

6. 12341, U.E. Ambient Air. Standard Gravimetric Measurement Method for the Determination of the PM10 or PM2.5 Mass Concentration of Suspended Particulate Matter. 2014. Available online: https://infostore.saiglobal.com/preview/98705579385.pdf?sku=857774_saig_nsai_nsai_2040554 (accessed on 10 October 2019).

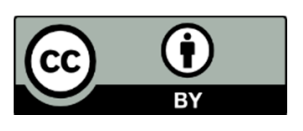

(C) 2019 by the authors. Licensee MDPI, Basel, Switzerland. This article is an open access article distributed under the terms and conditions of the Creative Commons Attribution (CC BY) license (http://creativecommons.org/licenses/by/4.0/). 